\title{
THE PROBLEM OF PROGRESS IN ECONOMIC SCIENCE
}

\author{
By \\ VINCENT J. TARASCIO \\ University of N. Carolina, Chapel Hill
}

The purpose of this paper is to examine scientific economic enterprise from the point of view of theory choice and methods. Essentially 1 shall argue that progress in economics is not solely a matter of discovering «better» theories within the context of the existing methodology, but rather, the failure of economic science to live up to expectations is the consequence of ignoring some fundamental methodological issues. In particular, economists have not often practiced what they have preached as positivists, and in cases where they have, the philosophy has not been applicable. In other words, the rational basis for scientific economic enterprise becomes questionable if one looks at the relationship between practice and philosophy.

\section{Scientific Enterprise : The Natural and Social Sciences}

Scientific enterprise is often assumed to be one of the most rational of all human enterprises. Given certain ends, the most appropriate means for achieving those ends are chosen. In science the means are the procedures used for scientific analysis and the rationalization of these procedures falls in the realm of methodology or philosophy of science. Although scientific enterprise possesses a philosophical basis, it does not follow that all scientists are methodologists or philosophers of science. In practice one finds that most working scientists regard the philosophy of science with an attitude which varies from indifference to one of a complete waste of time.

This attitude towards the philosophical basis for their activities is understandable; working scientists are interested in the subject of investigation, rather than in the nature of their own activities. Also, as scientists they are interested 
in definitive results and philosophical discourse is hardly ever definitive. In other words, the procedures used by scientists may have a rational basis, but its articulation is not a matter of concern for the working scientist. Instead successive generations of scientists simply have accepted such procedures as a traditional part of their training ${ }^{l}$.

Hence we are led to a distinction between scientific enterprise as rational activity as opposed to traditional activity. It seems that scientists as «receivers» of an implied philosophical doctrine fall into the latter category : they do what simply because they were taught to do things according to the conventions of their disciplines ${ }^{2}$. Given such an environment, if a theory «fails», according to some conventional criterion in a particular discipline, the problem is one of finding a «better» theory. In the natural sciences, progress has been characterized by such a process of finding «better» theories. The methodology of science has remained in tact.

Philosophers of science have attempted to rationalize such procedures, and by characterizing them have attached labels to them, such as «positivism». In the natural sciences the working scientist need not be concerned with the speculations of philosophers. What matters is that what he does produces results, according to some criterion. And the progress in the natural sciences certainly has been such that their procedures hardly need defending. This is not to say that the natural sciences have not been without «crises» in theory, but that such «crises» were not, in general, such as to undermine the epistomological foundations of those sciences.

In we turn to the social sciences, say economics, we find the situation altogether different. To begin, methodological disputes have raged among the practitioners of the science. The critics of classical economics, such as Comte, Marx, and the German historical economists, as well as the critics of neoclassical economics, such as the American Institutionalists, were not content to attact the theories, but also the methodology of those schools ${ }^{3}$. This situation exists today

1. The procedures of science will be discussed in detail below. What is important is that the methodology of sciences is hardly ever a formal explicit part of a scientist's training, but instead, is reflected in the procedures of analysis, and therefore implicit.

2. There is little wrong with this circumstance for once principles are established it would be redundant to rationalize them.

3. For a detailed discussion of the methodological review of these writers see : Vincent J. Tarascio, Pareto's Methodological Approach to Economics (Chapel Hill : The University of North Carolina Press, 1968), pp. 15 - 29. 
among some of the critics of orthodox economics, although to a much lesser extent. Nevertheless, by the turn of this century, the methodological debates had virtually ended and, in economics, the procedures of the natural sciences, particularly those of the physical sciences, held sway. To the extent that methodological differences have existed among writers such as Machlup, Hutchinson, Friedman and Samuelson, in recent years, they have been differences within the context of the dominant philosophy in all sciences, positivism, which currently prevails in economics ${ }^{4}$.

In general, the attitude of economists regarding «crises» in economic theory has been the same as their counterparts in the physical sciences, a matter of finding a «better» theory. And so it was with the so-called Keynesian revolution, it being a revolution in theory not methodology.

What is importants the consensus among economists that if theory «fails» there is something wrong with the theory, rather than with the methodology. Yet, progress in economics, and the social sciences in general, has been much slower than that of the natural sciences, even though adherence is to the same philosophy as in the natural sciences. This slow progress in the social sciences has been attributed to such factors as the complexity of the subject matter, interdependence, changing «background conditions», and so on. Such factors raise the possibility that the problem of progress and its solution may not lie in theory alone, but in the social scientists 'methodological approach to the study of human society.

The philosophy of positivism derived from practice in the physical sciences and was adopted by economists (and ,later, other social scientists) as their own, because of the impressive results achieved in the physical sciences. Although the «demonstration effect» was sufficient grounds to adopt the methodology of the physical sciences early in the development of economics as a science, the question now arises as to whether or not experience has proven it to be the correct choice. Two possibilities are presented to us. First, that practice in economics has conformed to philosophy, i.e., economists have practiced what they have preached. Secondly, practice has not conformed to philosophy. In the first case, if progress

4. The protean word «Positivism» requires some definition. Without assigning too strict a definition to the term, 1 mean the philosophy of positive empirical science, which prescribes certain procedures in order to «objectify» subjective experience, which accepts the efficacy of atomism as a source of knowledge, and reflects the influence of the Cartesian subjectobject dichotomy. Within the broad context of positive empirical science, there are subgroups such as the logical positivists, the operationalists, etc., which emphasize one point of view or another, and whose views are not ge nerally shared by all working scientists. 
has been slow, it may be that the philosophy does not apply to the social sciences and therefore the efficacy of practice is problematic. In the second case it may be that the philosophy $\mathrm{cann}$ ot be applied to the social sciences, and theorefore it is irrelevant ${ }^{5}$. In the natural sciences there is a strong argument for rejecting the second case based on experience. In the social sciences, as 1 shall argue below, it turns out that the selection process by which theories are accepted rejected differs from that of the natural sciences, even though the social sciences nominally subscribe to the same standards or selection as the natural sciences.

The above distinction may be posed in another way. In the natural sciences, for the reasons given above, there is no need to raise the distinction between practice and philosophy, indeed the latter is not a matter of concern and can be ignored (except by philosophers of science). Philosophy has attempted to conform to the practice. In economics, practice has attempted to conform to the philosophy of positivism.

\section{Theory Choice Economics}

Theory choice in economics serves as an example of a case of practice not conforming to philosophy. The issue of theory choice, the selection process by which theories are accepted and rejected, is central to positivism, for a salient feature of positivism has been the articulation of rules, tests, procedures, etc. for objectifying «subject» experience. In other words, an important goal of positivism is to eliminate the subjective element in theory choice.

In a recent paper, Bruce Caldwell and I examined various criteria used for theory choice by positive empirical science. With respect to the empirical ciriterion of predictive adequacy, several aspects, such as initial conditions, general laws and change and other problems were examined. We concluded, in part :

For theory choice on empirical grounds to be workable in any discipline, general laws must be present, initial conditions should be relatively few in number and easily checkable, and data must be trustworthy and complete. There are numerous instances in economics in which such requirements are not satisfied ${ }^{6}$.

5. In reality one expect to find examples of both since cases are not so clear cut.

6. Vincent J. Tarascio and Bruce Caldwell, «Theory Choice in Economics : Practice and Philosophy,» Journal of Economic Issues, Vol. XIII, No 4 (Dec. 1979)., pp. 9831005 . 
We then went On to examine nonempirical criteria for theory choice such as logical consitency, elegance, extensibility, generality, multiple connectedness, heuristic value, and simplicity. Our concern was whether or not theory choice could be based on nonempirical grounds. We concluded :

The implications of this discussion of nonempirical criteria to theory choice are as disheartening as the earlier discussion of predictive adequacy; it seems that these criteria can only be used for the justification or rationalization of theories, rather than for the choice from among competing theories.

Yet in spite of these obstacles, theory choice does take place in economics. The problem is that it seldom follows the canons of positive empirical science.

We then went on to examine the nature of selection process as it is practiced, rather than its phylosophy. We argued that «while incorporating elements from both the standard (positivistic) and growth of knowledge (Kuhn, Lakatos, Feyeraband, Toulmin)traditions regarding theory choice, it differs from both in emphasizing the distinction between objective existence of a contribution and its subjective acceptance as a point of a body of knowledge ...» Upon completion of our examination of various stages of the selection process we concluded :

Most important, however, is that the criteria for «rejecting» such theories are not those which have emerged in positivist philosophy of science, that is, disconfirmation, falsification, and so forth, either at the formal stage of evaluation, or the postpublication stage of objective existence. Both parts of the selection process involve primarily subjective factors of an interpretive nature. Indeed, the objective factors are relatively unimportant in the first stage and irrelevant in the second.

What has been discussed thus far serves an as example of where economic practice generally cannot and has not conformed to the tenets of positive empirical philosophy, regarding the central issue of theory choice. Therefore the history of economics as a science has not been patterned after the physical sciences on this issue.

Although theory choice in economics has not followed the example of the physical sciences, the framework of economic analysis has developed along the 
lines of rational mechanics, implying that the procedures of the physical sciences are appropriate for the investigation of human behavior. This development reflects the influence of «naturalism» on scientific economic thought, which deserves further consideration.

\section{The «Naturalistic» View of Economic Science}

During the 1960' $\mathrm{s}$ the distinction between the methodology of the social sciences and that of the natural sciences was debated among philosophers of science. Those who took the position that there was no logical basis for the distinction between the two were called «naturalists», and those who argued that the nature of the subject matter of the two types of science was such that they required different methodologies became identified as «phenomenologists» ${ }^{7}$. The point of view which argues that the subject matter of the social sciences is such that the study of human society requires its own methodology, different from that of the physical sciences, is quite familiar to economists and goes back at least to the German Idealistic tradition and those who came under its influence, such as the German Historical School and Marx. Later, the American Institutionalists, some of whom were also influenced by Idealistic philosophy, reflected a similar point of view. In any event, although orthodox economics has had its methodological critics during its development, the «naturalistic» view has remained dominant and is reflected in the current state of economics. This naturalistic orientation is identified with and indeed is an integral part of positivism.

Recently 1 reexamined this issue. In particular, 1 traced the influence of «naturalism» on economics, and how such theories have neglected the problem of uncertainty and change ${ }^{8}$. The tradition of economics has been an outgrowth of utilitarian philosophy and can be characterized as having been atomistic, rationalistic and materialistic. The first and third characteristics have a bearing on scope, the second on the methodology.

The rationalistic character of the tradition of economics is reflected in the concept of «economic man,» the assumed rational behavior of economic agents. 1 have argued that the concept of «economic man» was nothing other than a

7. For a collection of works dealing with both points of view see : Maurice Natanson, ed.' Philosophy of the Social Sciences (New York: Random House, 1963)

8. Vincent J. Tarascio, «Theories of Behavior and Public Policy», S p oudai, Vol. 27, No. 2. (1977), pp. 279-290. 
conceptualization of the observer' $s$ own thought process (reason) extended to the actor ${ }^{9}$. The appeal of «economic man» is that it fits very well the static equilibrium framework of economic analysis borrowed from mechanics ${ }^{10}$. Even the so called economic dynamics are special cases of statics and are mechanical in nature. The result is that economics is ill suited to deal with the problem of change a characteristic of human societies which is historical rather than mechanical in nature ${ }^{81}$. Change involving social phenomena lends historical uniqueness and concrete individuality to social phenomena which are often absent in the natural sciences. Consequently, the methods used in the natural sciences, although appropriate for them, are not adequate for social science analysis. In contrast to the dynamic mechanical approach, the historical approach considers each stage in the process of change as unique and possessing a concrete individuality.

To the extent that the mechanistic models in economics are applicable, they are applicable to situations where changing «background conditions» are absent. One such case is with studies relating to the past, since the past is «dead» and «frozen» in time. It is questionable as to whether or not such models are even appropriate for the analysis of the present, since what we know of think we know about the present is based on historical data, because of the lag involved in gathering «current» information. In a changing environment the present often turns out to be an extrapolation of the recent past. On the matter of forecasting the future, what will be, it turns out, also, that such models merely extrapolate the past.

The German historical school, recognizing the historical character of human society, i.e. its historical uniqueness and concrete individuality at each state in the process of change attempted to substitute the procedures of history for those of the physical sciences. Nevertheless, the results were equally unimpressive regarding what is and what will be. At least, the Germans recognized the historical character of human society and attempted to develop an appropriate methodology. On the other hand, economists continue to believe that the problem of change can be broached by «better» theories, more timely data, etc., and view the problem as one which can be resolved within the context of current (naturalistic) methodology. Yet this optimism has little basis in experience, because of the failure of the $\eta$ a $\mathrm{t} u \mathrm{r}$ a 1 sciences to deal with this problem successfully when confronted

9. Ibid., pp. 282-283.

10. Ibid.

11. For more on the historical nature of change see : Ibid., pp. $284-285$. 
with $\mathrm{it}^{12}$. Paradoxically, the methods of the natural sciences when applied to economic phenomena, are more suitable for the study of an unchanging past and therefore economic science is essentially most useful as economic history ${ }^{13}$.

Thus far 1 have reviewed two methodological issues in economics- theory choice and methods-which are fundamental from the point of view of science. 1 have argued that theory choice in practice does not follow the tenets of positive empirical science. A lack of correspondence between practice and philosophy points to the problems encountered in attempting to apply to a social science a philosophy which had its origins in the natural sciences. The existence of this lack of correspondence should tell us something about the applicability of positive empirical science to economics. Yet the problem has been swept under the rug.

The second issue relates to the efficacy of natural science methods for the social sciences. 1 have argued that in this case the view among economists has been that there is no $1 \mathrm{o} \mathrm{g} \mathrm{i} \mathrm{c} \mathrm{a} 1$ distinction between social and natural phenomena, and that the methods of the natural sciences are appropriate for the study of human society. This view corresponds to the «naturalistic» orientations of some philosophers of science, which have come under attack. In any event, in the natural sciences, unchanging «background conditions» are characteristic, so that dynamic-mechanistic theories are adequate. In the social sciences, historical change is characteristic and the tendency of economists to deal with historical change within the context of natural science methods has caused economics to be essentially a science of the past.

\section{Pareto on Scope}

During the turn of the century, Pareto, the positivist, insisted that theory

12. An example in the natural sciences is the mutation of virus which produce «new strains». Here the record for predicting «new strains» has been poor and a source of surprises as the economic world has been a source of surprises for economists. For more on these distinctions see : I b i d., pp. $284-285$.

13. Even as economic history, the record is dubious. Take, for example, the controversy surrounding the causes of the Great Depression and the conflicting views of Friedman and Schwartz, Temin, and Kindleberger, to mention a few. Cf. Friedman and Schwartz, M o n e t a r y His tory of the United States 1869- 1960 (Princeton: Princeton University Press, 1963) ; Peter Temin, Did Monetary Forces Cause the Great Depression (New York: W.W. Norton 1976) ; Charles P. Kindelberger, The World in Depression 1929-1939 (Berkeley : University of California Press, 1973). The problem is essentially one of scope, differences in scope causing differences in perceived causal relationships. 
choice in economics could follow along the lines of positive empirical science. This assertion was based on continuous examples from the physical sciences. Nevertheless, he too encountered the problem of change, but he insisted that the problem of changing background conditions could be resolved by expanding the scope of economics to include such background conditions as part of theory. Hence he was led to sociology, which for him represented a synthesis of all social phenomena, economic, political, religious, psychological, etc.

What is remarkable, Pareto recognized the historical nature of social change, and his sociology is essentially an interpretation of history. But Pareto would not accept the German conception of historical uniqueness and concrete individuality as the basis for historical research. Instead he argued that although institutions, values, etc. undergo continuous change over time, human personalities and propensities do not. Therefore the «constants» which seem to be lacking in history were merely the consequence of incomplete theory. In his research Pareto thought that he had discovered the means to reduce historical change to a special case of dynamic-mechanics, through wider scope (sociology) and a higher level of abstraction (theory of residues). As a result he was willing to concede any distinction to history and science.

On the matter of theory choice, Pareto did not go beyond his positivist contemporaries in his assertions that practice c o u ld follow philosophy, which amounted to little. But on the matter of change, Pareto ${ }^{14}$ raised a new wrinkle; namely that the apparent problem of historical change was the consequence of incomplete synthesis, which could be broached through broader scope of analysis. With respect to the problem of historical change Pareto went beyond mere assertion; he devoted approximately 15 years to his theory of society which culminated in the $\mathrm{T} \mathrm{r}$ a $\mathrm{t} \mathrm{t}$ a $\mathrm{t} \mathrm{o}$, consisting of over one million words.

So Pareto offered the economics profession a solution to the problem of historical change with his sociology. Unfortunately, Pareto went one way and the profession went another way, with its traditional emphasis on narrow scope. Since Pareto's theory was not subjected to the tests of positive empirical science, which he himself had claimer as possible, it is not possible to know if his approach

14. Vilferdo Pareto, Trattato di sociologia gé nérale. 4 vols. (Firenze: Barbera, 1916). Translated into English as: The Mind and Sosciety, translated and edited by Arthur Livingston, 4 vols. (New York : Harcourt, Brace and Com- pany, 1935). See : Vol. 1, Chapter 1. 
to the problem was correct ${ }^{15}$. Instead all that can be said is that he left us with an intriguing possibility. Pareto remained a positivist to the very end. And over half a century later, these two fundamental problems, theory choice and historical change, remain with us.

\section{Conclusion}

In view of the above, one might ask: In what sense is economic science a rational enterprise? The issues discussed certainly do not come as any surprise to practicing economists, yet the prevailing view seems to be that the solutions to these problems lie in corrective improvements within the content of naturalistic methodology. The prevailing philosophy of science in economics is not and never has been a product of practice in the social sciences, as was the case in the natural sciences. Instead it was transplanted into economics, and later the other social sciences, because of a demonstration effect : the impressive progress of the natural sciences. Therefore acceptance was a consequence of belief rather than experience. One can excuse the early positivists, such as Pareto, since they were influenced by their environment and it seemed to them that, as Comte had argued earlier, there was only one Science to be applied to all phenomena both social and natural. What is remarkable is that this belief has persisted so long, in spite of the fact that progress in the social sciences has failed to keep up with that of the natural sciences, or even to live up to expectations.

The solution to the problem of progress in the social sciences, if one exists, has been an elusive one. Certainly, the solutions offered by the early critics of orthodox methodology turned out to be equally unimpressive in practice. Nevertheless, the currently uneasy complacency among practioners that somehow «better» theories within the contexit of the prevailing methodology will somehow lead to greater progress in our sciences will likely result in further disappointments.

15. Here again is an example of a scientific work whose acceptance or rejection did not follow the procedures of positive empirical science. Indeed even where parts of the sociology, namely particular theories were accepted or rejected by the social sciences, influencing factors were largely subjective. For more in this subject see : Vincent J. Tarascio. «La Sosciologie de Pareto aux Etats - Unis, «Recherches Sociologiques No 2 (May 1975), pp. $261-274$. 